\title{
COMPARISON OF OBSTETRICAL OUTCOME WITH LABOR INDUCTION AGENTS USED AT TERM
}

\author{
By \\ Mohamed El-Sebaey El-Awdy, Ahmed Mohamed Al-Sadek and Mofeed \\ Fawzy Mohamed ${ }^{1}$
}

Obstetrics and Gynecology Department, Faculty of Medicine, Al-Azhar University, Cairo, Egypt

E-mail: m_elsebaey@gmail.com

\begin{abstract}
Background: Induction of labour has risen gradually in modern obstetrics all over the world. It is more predominant in developed countries (around 20\%) than developing countries.

Objectives: To evaluate the outcome of induction of labor in primiparous, multiparous women and the risk of cesarean delivery associated with induction.

Patients and methods: This study included 200 patients attending to Obstetrics and Gynecological Department at Al-Hussein University Hospital for delivery and Al-Sinblawein General Hospital from September 2019 to April 2020. The patients were classified into two equal groups according to success of induction:
\end{abstract}

Group 1 was given misoprostol vaginally after rupture of membrane, group 2 patients was give oxytocin by slow infusion after rupture of membrane. Patients with gestational age less than 37 weeks, previous cesarean delivery, with breech presentation and age above 40 years were excluded.

Results: There was a statistically significant difference between group 1(misoprostol) and group 2 (oxytocin) regarding induction of labor with mean interval between hours was higher in group 2.

Conclusion: Vaginal misoprostol was effective, easy to administer, safe method and superior to oxytocin for induction of labor.

Key Words: Labor, Misoprostol, Oxytocin.

\section{INTRODUCTION}

Indications for induction of labor are quite similar. Those indications can be divided into medical or elective indications. Medical indications include post term pregnancy 42 weeks of gestation or over, prolonged rupture of membrane $>24$ hours, hypertension, pre-eclampsia, intra-uterine growth restriction, intrauterine fetal distress, gestational diabetes mellitus, macrosomia, iso-immunization, intra-uterine fetal death and many others. Elective indications mainly include post term pregnancy 40-41 weeks of gestation and oligohydramnios (Kavita et al., 2014).

Induction of labor has been concluded in some articles that it has an association with an increased risk of cesarean delivery. Considering the fact that the rate of cesarean section has risen dramatically all over the world. In that case, it is very important to investigate the associated risk 
of cesarean section with induction of labour, to get a full understanding and to careful consider this risk upon inducing women (Jenitha et al., 2013).

The developing world, prolonged and often neglected labor is associated with high levels of mortality and morbidity because of lack of appropriate health care, in particular antibiotics and the surgical facilities to perform a The management of spontaneous labor In remains an important issue cesarean section (Wing, 2010).

Cervical status is one of the most important factors for predicting the likelihood of successfully inducing labor. For this reason, a cervical examination should be performed before initiating attempts at induction. There are several cervical scoring systems available for this purpose (eg, Bishop System; Fields system; Burnett, Caldor, and Friedman modifications of the Bishop system (Kamel et al., 2019).

The diagnosis of active labour is dependent on a careful cervical assessment to define dilatation, effacement, consistency, position and station of the head. These are more important than "soft" indicators such as regular contractions, show or even amniotic membrane rupture (Kavita et al., 2014).

Oxytocin is less successful for labor induction when used in women with uneffaced and undilated cervices. Therefore a ripening process should be used prior to oxytocin induction when the cervix is unfavorable. The two major methods are: (1) mechanical (physical) interventions, such as disruption of the fetal membranes or insertion of dilators or a balloon catheter (2) application of cervical ripening agents, such as prostaglandin compounds (World Health Organization, 2014).

\section{Methods of augmentation of labour:}

- Artificial rupture of membranes (ARM)

- IV oxytocin infusion

- Misoprostol (Kavita et al., 2014).

\section{SUBJECTS AND METHODS}

This study was conducted at AlHussein University Hospital and AlSinblawein General Hospital.

- This study included (200) patients attending to Obstetrics and Gynecological Department for delivery September 2019 to April 2020.

- The patients were classified into two equal groups according to success of induction: Group 1 was given misoprostol vaginally after rupture of membrane group 2 was give oxytocin by slow infusion after rupture of membrane.

\section{Exclusion criteria:}

1. Gestational age less than 37 weeks.

2. Previous cesarean delivery.

3. Breech presentation.

4. Age above 40 years.

\section{Laboratory Investigations:}

Complete blood picture, fasting and two hours postprandial blood sugar, liver functions, kidney functions and coagulation profile.

Ethical considerations: The study was approved by the Ethics Committee of the Faculty of Medicine, Al-Azhar University. 
Informed consent was obtained from each participant.

\section{Statistical analysis:}

The data were coded, entered and processed on computer using SPSS (version 23). Mean, standard deviation, range, frequency, and percentage were used as descriptive statistics.
Chi-Square test $\mathrm{X}^{2}$ was used to test the association variables for categorical data.

Student's t-test was used to assess the statistical significance of the difference between two population means in a study involving independent samples.

$\mathrm{P}$ value was considered significant When $\mathrm{P} \leq 0.05$.

\section{RESULTS}

There was a statistically significant difference between Group 1 (misoprostol) and Group 2 (oxytocin) regarding Gravdity and parity, also There was a statistically significant difference between group 1 (misoprostol) and group 2 (oxytocin) regarding induction of labor and there was a statistically significant decrease in interval between maneuver/ Labour (hours) among group 1 than group 2 (Table 1).

Table (1): Comparison between group 1 (misoprostol) and group 2 (oxytocin) regarding Gravdity and parity

\begin{tabular}{|c|c|c|c|c|c|}
\hline \multicolumn{3}{|l|}{ Parameters } & $\begin{array}{c}\text { Group 1 } \\
\text { (Misoprostol) } \\
(\text { No.= 100) }\end{array}$ & $\begin{array}{c}\text { Group 2 } \\
\text { (Oxytocin) } \\
(\text { No.= 100) }\end{array}$ & $\begin{array}{c}P . \\
\text { value }\end{array}$ \\
\hline \multirow{2}{*}{ Gravdity } & \multicolumn{2}{|c|}{ Rang } & $1-6$ & $1-5$ & 0.000 \\
\hline & \multicolumn{2}{|c|}{ Mean \pm SD } & $2.17 \pm 1.12$ & $2.93 \pm 1.121$ & 1 \\
\hline \multirow{2}{*}{ Parity } & \multicolumn{2}{|c|}{ Rang } & $0-4$ & $0-4$ & 0.000 \\
\hline & \multicolumn{2}{|c|}{ Mean \pm SD } & $1.23 \pm 1.058$ & $1.77 \pm 1.08$ & 1 \\
\hline \multirow{4}{*}{$\begin{array}{c}\text { Induction of } \\
\text { labor }\end{array}$} & \multirow{2}{*}{$\begin{array}{c}\text { success } \\
\text { of } \\
\text { induction } \\
\end{array}$} & No. & 79 & 65 & \multirow{4}{*}{0.027} \\
\hline & & $\%$ & $79.0 \%$ & $65.0 \%$ & \\
\hline & \multirow{2}{*}{$\begin{array}{c}\text { failed } \\
\text { induction }\end{array}$} & No. & 21 & 35 & \\
\hline & & or & $010 \%$ & $350 \%$ & \\
\hline $\begin{array}{c}\text { Interval } \\
\text { between } \\
\text { Maneuver } \\
\text { /Labor(hours) }\end{array}$ & \multicolumn{2}{|c|}{ Mean \pm SD } & $7.5 \pm 1.1$ & $10.54 \pm 1.6$ & 0.001 \\
\hline
\end{tabular}

There was no statistically significant difference between group 1 (misoprostol) and group 2 (oxytocin) regarding maternal complications, also there was no statistically significant difference between group 1 (misoprostol) and group 2 (oxytocin) regarding neonatal complications (Table 2). 
Table (2): Overall distribution of maternal and neonatal complications

\begin{tabular}{|c|c|c|c|c|c|}
\hline $\begin{array}{ll}\text { Parameters } & \text { Groups } \\
\end{array}$ & \multicolumn{2}{|c|}{$\begin{array}{c}\text { Group 1 } \\
(\text { misoprostol)) }\end{array}$} & \multicolumn{2}{|c|}{$\begin{array}{l}\text { Group } 2 \\
\text { (oxytocin) }\end{array}$} & $\begin{array}{c}\text { P. } \\
\text { value }\end{array}$ \\
\hline Maternal complications & No. & $\%$ & No. & $\%$ & \multirow{7}{*}{0.08} \\
\hline Nausea/vomiting & 47 & 47 & 35 & 35 & \\
\hline Diarrhoea & 6 & 6 & 0 & 0 & \\
\hline Headache & 0 & 0 & 9 & 9 & \\
\hline Fever & 35 & 35 & 30 & 30 & \\
\hline Shortness of breath (SOB) & 6 & 6 & 8 & 8 & \\
\hline Post-partum haemorrhage (PPH) & 10 & 10 & 15 & 15 & \\
\hline Neonatal complications & No. & $\%$ & No. & $\%$ & \multirow{5}{*}{0.43} \\
\hline Irregular foetal heart rate & 9 & 9 & 6 & 6 & \\
\hline meconium stained liquor & 40 & 40 & 41 & 41 & \\
\hline Suction/oxygen resuscitation & 20 & 20 & 25 & 25 & \\
\hline NICU admission & 20 & 20 & 23 & 23 & \\
\hline
\end{tabular}

\section{DISCUSSION}

A variety of pharmacological and nonpharmacological methods are used for induction of labor (IOL). Pharmacological methods include oxytocin, prostaglandin (PG) analogues and smooth muscle stimulants such as herbs or castor oil, whereas non-pharmacological methods include mechanical methods such as digital stretching of the cervix and sweeping of the membranes, hygroscopic cervical dilators, balloon catheters, artificial rupture of the membranes and nipple stimulation (Acharya et al., 2017).

Induction is carried out by oxytocin in case cervix is favorable, that is, Bishop score of 6 or more, whereas in case the cervix is unfavorable, then usually a PG is placed in vagina or cervix to ripen the cervix to initiate the uterine contraction (Gülmezoglu et al., 2012).

In comparison to other PGs, misoprostol is cheap, widely available, stable at room temperature and has few side effects (Winikoff et al. 2010).

This study showed that there was a statistically significant difference between group 1 (misoprostol) and group 2 (oxytocin) regarding induction of labor. Success of induction was higher among group 1 (misoprostol) than group 2 (oxytocin).

This agreed with Acharya et al. (2017) who aimed to find out the maternal and fetal outcomes after induction of labor with misoprostol and oxytocin. There was a hospital-based observational study carried out at Paropakar Maternity and Women's Hospital, Nepal. Misoprostol of $25 \mu \mathrm{g}$ was inserted in posterior fornix of vagina or oxytocin infusion was started from 2.5 units on whom induction was decided. Maternal and fetal/neonatal outcomes were observed. They found that normal delivery in patients administered only by misoprostol was higher $(71.1 \%)$ than oxytocin $(66 \%)$ group.

According to different studies, the incidence of normal delivery was similar to this study (Dongol et al., 2010).

Chitrakar (2012) have found that cesarean section rate was significantly less in misoprostol than other methods for induction. 
A study reported that though more incidences of caesarean section were encountered with oxytocin, it appeared to be safe (Tsakiridis et al., 2020).

However, another study reported that the incidence of cesarean section was similar in both oxytocin and misoprostol groups. No differences were observed between groups in perinatal and postpartum adverse outcomes, and misoprostol use was considered safe (Jamali et al., 2020).

It was seen that misoprostol was quite frequently used in this study. Misoprostol is safe, cost-effective and easy to administer and store because of which it has become a drug of choice in poor nations, and $25 \mu \mathrm{g}$ intravaginal misoprostol has been included in the World Health Organization (WHO) complementary list as drug for IOL (World Health Organization, 2014).

Oxytocin and prostaglandins are the most frequently used pharmacological agents for induction of labor. Oxytocin is the standard agent for labor induction. It is produced endogenously chiefly in the hypothalamus and released from the posterior pituitary gland. Although oxytocin infusion is accepted widely as a safe and effective labor induction method, its success is highly dependent on the condition of the cervix at the beginning of the induction (Jamali et al., 2020).

This study showed that there was a statistically significant decrease in interval between maneuver / Labor (hours) among group 1 than group 2.

This agreed with Shabana et al. (2017) who aimed to compare the efficacy and safety of misoprostol with oxytocin infusion for induction of labor in women.

Osman Balci et al. (2011) found significant difference in time from induction to delivery between misoprostol group and oxytocin group. Gülmezoglu et al. (2013) stated the IDI is significantly shorter in the misoprostol group than in the oxytocin group.

Winikoff et al. (2010) found that the IDI was shorter with misoprostol than with oxytocin.

However, a study by Alfirevic et al. (2016) found that the time interval from IDI was similar in the misoprostol group and in the oxytocin group.

Our result was not in agreement with the study of Girault (2020) who found a significant difference between the misoprostol and the oxytocin group, with longer IDI in the misoprostol group compared with oxytocin. Both misoprostol and oxytocin were associated with several maternal complications. Overall, maternal morbidity resulting from misoprostol was found to be nausea/vomiting, diarrhea, headache, fever, shortness of breath (SOB) and Postpartum hemorrhage (PPH) with nausea/vomiting being the most common followed by fever.

Alfirevic et al. (2016) have reported uterine hyperstimulation and tachysystole with misoprostol. There is less risk of hyperstimulation with lower dose of misoprostol, but it also decreases the effectiveness for labour induction (Shakya et al., 2010).

The side effects found in this study was similar to another study conducted in 
Nepal (Dongol et al., 2010) except for fever, which was seen in only one case.

Our study also found no significant difference between the two groups in the occurrence of maternal complications. These results were similar to the results of Gülmezoglu et al. (2012) who found no significant difference in the occurrence of specific drug side effects, for example, nausea, vomiting, and diarrhea between the two study groups. Girault (2020) found no significant difference in both misoprostol and oxytocin groups regarding maternal complication.

This study showed that regarding neonatal outcomes, the overall occurrence of meconium stained liqor (MSL) was found to be high. Other complications seen were requirement of suction for resuscitation, NICU admission, and irregularity in FHR. This was similar to Gülmezoglu et al. (2012) who found very less difference was seen between misoprostol and oxytocin group.

Chitrakar (2012) found that $25 \mu \mathrm{g}$ intravaginal misoprostol reduces passes of meconium in foetus and is safe. A study by Tsakiridis et al. (2020) suggests that even though administration of misoprostol increases the passes of meconium in the foetus, neonatal adverse effect is less even at higher doses. Gülmezoglu et al. (2012) reported that there is an increase of risk for stillbirth and perinatal mortality after 41 weeks of gestational age.

In our study, there was no significant difference between the two groups regarding neonatal complications. This agrees with Mbaluka et al. (2014) who found no difference in neonatal outcomes between the studied groups.
In our study, the two groups were similar in terms of neonatal admission to the ICU (NICU). Our results were in agreement with those of Girault (2020), who found that the misoprostol and oxytocin groups were similar in terms of admission to NICU.

A study by Alfirevic et al. (2016) found a no significant trend toward greater NICU admission among infants born to mothers receiving misoprostol compared with the oxytocin group.

\section{REFERENCES}

1. Acharya, T., Devkota, R., Bhattarai, B. and Acharya, R. (2017): Outcome of misoprostol and oxytocin in induction of labour. SAGE Open Medicine, 5, 2050312117700809.

2. Alfirevic Z., Keeney E., Dowswell, T., Welton N. J., Medley N., Dias S. and Caldwell M. (2016): Which method is best for the induction of labour? A systematic review, network meta-analysis and cost-effectiveness analysis. Health technology assessment. Last accessed 14 Sep. 2020.

3. Chitrakar NS. (2012): Comparison of misoprostol versus dinoprostone for preinduction cervical ripening at-term. J Nepal Health Res Counc., 10: 10-15.

4. Dongol A, Shakya S, Chawla C. (2010): Safety and efficacy of misoprostol for induction of labour. J Nepal Health Res Counc., 8(1): 27-30.

5. Girault A. (2020): Rupture des membranes à terme avant travail. Recommandations pour la pratique clinique du CNGOF-Méthodes de déclenchement. Gynécologie Obstétrique Fertilité \& Sénologie, 48(1): 48-58

6. Gülmezoglu, A. M., Crowther, C. A., Middleton, P. and Heatley, E. (2012): Induction of labour for improving birth outcomes for women at or beyond term. Cochrane database of systematic reviews. Last accessed 16 Aug. 2020.

7. Jamali, M., Bakhtiyari, M., Arab F. and Mirzamoradi M. (2020): Misoprostol 
complications in second-trimester termination of pregnancy among women with a history of more than one cesarean section. Obstetrics \& Gynecology Science, 63(3), 323-338.

8. Jenitha B. and Subbiah M. (2013): A comparative study of low dose Misoprostol (PGE1) with intercervical Dinoprostone (PGE2) gel for cervical ripening and labour induction, Journal of Evolution of Medical and Dental Sciences, 10.14260.

9. Kamel, R., Montaguti, E., Nicolaides, K. H., Soliman, M., Dodaro, M. G., Negm, S. and Youssef, A. (2019): Contraction of the levator ani muscle during Valsalva maneuver (coactivation) is associated with a longer active second stage of labor in nulliparous women undergoing induction of labor. American journal of obstetrics and gynecology, 220(2): 189-e1.

10. Kavita G, Jaya K, and Disha A (2014): Induction of Labor: A Review Indian Journal of Clinical Practice, 24(2):400-406

11. Osman B. Alaa S. Mahmoud A., Ali A. and Mehmet C. (2011): Comparison of induction of labor with vaginal misoprostol plus oxytocin versus oxytocin alone in term primigravidae, The Journal of Maternal-Fetal \& Neonatal Medicine, 24(9): 1084-1087.

12. Shabana AA, El Kilani OA, El Khouly NI. and Tayel SM (2015): Comparison of oral misoprostol and oxytocin for labor induction in prelabor rupture of membranes at term. Menoufia Med J., 28:239-44
13. Shakya R, Shrestha J. and Thapa P. (2010): Safety and efficacy of misoprostol and dinoprostone as cervical ripening agents. JNMA J Nepal Med Assoc., 49(177): 33-37.

14. Tsakiridis I., Mamopoulos A., Athanasiadis, A. and Dagklis T. (2020): Induction of Labor: An Overview of Guidelines. Obstetrical \& Gynecological Survey, 75(1): 61-72.

15. WHO recommendations for induction of labour. (2011): World Health Organization: Geneva; https://www.who.int/reproductivehealth/public ations/maternal_perinatal_health/97892415011 56/en/ last accessed 22 September 2020.

16. World Health Organization (2014): Preparations WECoSfP - quality assurance of pharmaceuticals: meeting a major public health challenge.

https://www.who.int/reproductivehealth/public ations/maternal_perinatal_health/38292412546 /en/ last accessed 22 September 2020.

17. Wing DA. Induction of labor. In: Queenan JT, Hobbins JC. and Spong CY. (2010): Protocols for high-risk pregnancies. Hoboken, NJ: Wiley-Blackwell. 140-147.

18. Winikoff, B., Dabash, R., Durocher, J., Darwish, E., Ngoc, N. T. N., León, W. and Blum, J. (2010): Treatment of post-partum haemorrhage with sublingual misoprostol versus oxytocin in women not exposed to oxytocin during labour: a double-blind, randomised, non-inferiority trial. The Lancet, 375(9710): 210-216. 


\section{المقارنة بين نتائج العو امل المحفزة للو لادة في الأجنة مكتملة التكوين}

محمد السباعي العوضي محمد، أحمد محمد الصادق، مفيد فوزي محمد قسم أمراض النساء و التوليد، طب الأزهر بالقاهرة

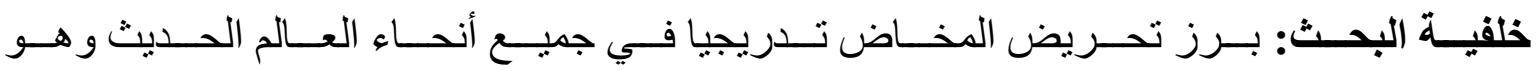
مسيطر أكثر في أنحاء الدول الدتقدمة بنسبة 20 بالمئة أكثر من الدول النامية.

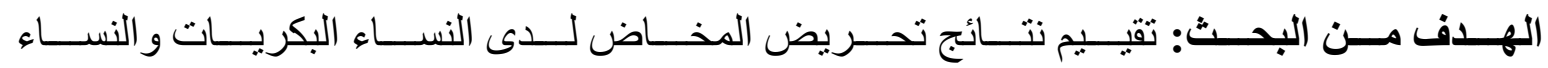

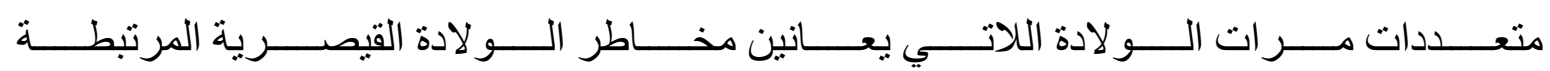
بالتحريض.

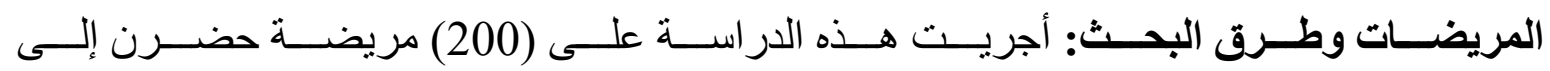

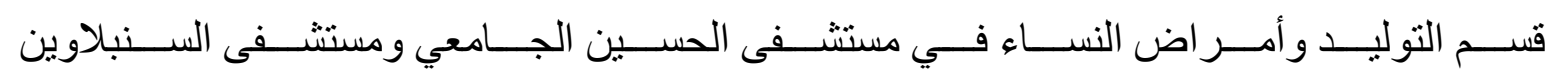

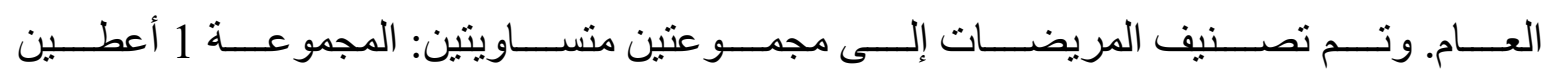

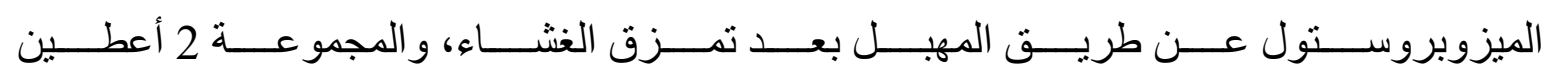
الأوكسيتوسين بالتسريب البطيء بعد تمزق الغشاء.

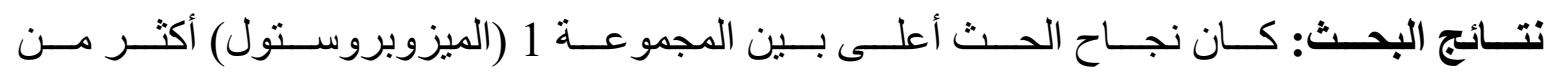

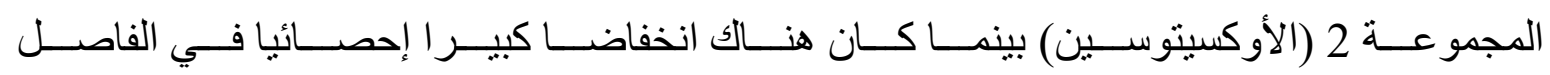

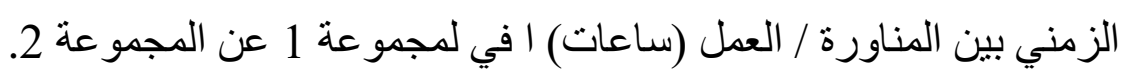

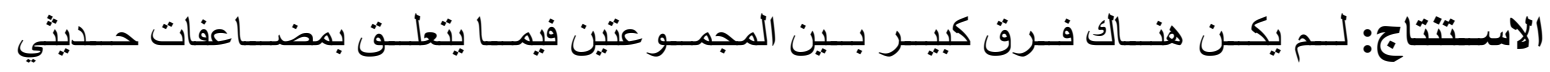
الو لادة. 